\title{
BACTEREMIAS POR BACILOS GRAM-NEGATIVOS *
}

\author{
Adrelirio J. R. Gonçalves ** Leopoldo F. Saldanha *** Sílvio Henrique $*$ *: \\ Marcos Hoctte $: * * *$ Vitorino M. dos Santos $* * *$ e Lucia Emi Suzuki ****
}

São apresentados 31 casos de bacteremia por gram-negativos. assunto que. vem merecendo muita atenção dos pesquisadores nos últimos anos. Os organismos etioiógicos mais importantes que apareceram em igualdade de freqüência foram Escherichia coli e Klebsiella-Aerobacter, sendo responsáveis por 58\% do total das infeccóes, seguidos por Pseudomonas.

$A$ porta de entrada mais freqüente foi o trato urinário em $61,3 c_{c}$ dos casos.

A infecção foi mais comum no sexo masculino e a faixa etária de 50 a 60 anos predominou.

o uso prévio de antibióticos foi um fator predisponente muito importante. seguido pelo uso de esteróides e citostáticos. As principais doenças predisponentes foram diabetes mellitus e neoplasias malignas.

Os principais fatôres precipitantes foram a manipulação do aparelho uri. nário, com infecçāo prévia ou desencadeada. cirurgia do aparelho digestivo, uropatia cbstrutiva e obstrucão biliar.

As principais manifestaçoes clinicas foram a presença de jebre, calafrios e hipotensão arterial.

A complicação mais freqüente foi o choque bacteriano que incidiu em $58 \%$ dos casos, aproximadamente três vêzes aquela relatada na literatura. As outras foram a insuficiência renal aguda, superinfeccão e infeccão pulmona. metastática.

Considerações terapéuticas gerais e esquemas de antibióticos são propoitos para êstes casos.

A mortalidade da bacteremia simples foi de $30,7 \%$ e quando associada an choque elevou-se para $72,2 \%$. As infeccóes por Pseudomonas foram $100 \%$ fatais.

\section{INTRODUÇÃO}

O estudo das bacteremias por gram-negativos é incontestàvelmente assunto de grande importância, em primeiro lugar pelo aumento crescente desta patologia em vários hospitais gerais de todo o mun. do, ccmo se verifica pelas inumeras publi.caçōes que surgiram a èsse respeito nos últimos anos $(2,3,4,5,6,7,8$ e 10$)$, assin como pela possibilidade de ocorréncia de quadros graves no inicio ou durante sua evolução. Êste crescente aumento de casos de bacteremia pcr gram-negativos pode ser explicado pelo uso cada vez maior de antibióticos e de medicacão imunossupressora, pelo alargamento da cirurgia. pela maior sobrevivência de doentes portadores de doenças malignas, e essencialmente por conidições que alteram profundamente o estado imunológico do hospedeiro $(3,4,6,9$ e 11$)$.

* Trabalho realizado nc Hospital dos Servidores do Estado

* Médico Assistente do serviço de Climica Médica do H. S. E. Do Hospital Isolamento Francisco de Castro.

*:* Ex-Residentes do Servico de Clinica Médica do H. S. E.

*** Residentes do Serviço de Clínica Médica do H. S. E. 


\section{MATERIAL}

O material consta apenas de 31 casos, catalogados no período de 1962 a 1968 através de critérios clínico e bacteriológico, êste baseado na presença de duas hemoculturas positivas e o primeiro em dados anamnésticos e do exame físico. O número de bacteremias por nós observado neste período é muito maior que o material que será analisado; no entanto, uma falta de documentaçāo essencialmente bacteriológica nos impediu de incluí-lo.

\section{ORGANISMOS ETIOLÓGICOS E PORTA DE ENTRADA}

Em nossa experiência Escherichia coli. e Klebsiella-Aerobacter foram os organismos causadores mais freqüentes; ambos ocorreram em uma percentagem de $29 \%$ dos casos estudados, o que nos leva a concluir que mais da metade das bacteremias por gram-negativos é cauśada por êsses dois germes que compõem o grupo coli-aerógenes.

Nos últimos anos tem-se notado uma incidência maior de infecções do grupo Klebsiella-Aerobacter (1). Clàssicamente, sabe-se que o grupo Coli é responsável por cêrca de $50 \%$ dos casos $(4,8)$, fato não verificado em nossa série, em que foram igualmente freqüentes êsses organismos como agentes etiológicos.

Pseudomonas aeruginosa nos últimos anos tem ocupado o terceiro lugar na escala de frequiência, deslocando Proteus para 0 4" lugar. Provàvelmente êsses desvios biológicos ocorrem por seleçầo de germes ou espécies cada vez mais resistentes e que agem freqüentemente por meca- nismos de superinfecção. Em seguida, pela escala de freqüência, encontramos associaçōes de $E$. coli $+P$. aeruginosa, $E$. coli + Kiebsiella. Paracolobactrum e Alcaligenes fecalis são germes de menor incidência. Técnicas anaeróbias não foram. realizadas senco talvez um dos motivos pelos quais não tenham sido encontrados Bacteroides.

A porta de entrada mais freqüiente foi o trato urinário em $61,3 \%$ dos casos, vindo em seguida o trato gastrointestinal. Pele, trato respiratório, aparelho genital feminino foram as portas de entrada menos freqüentes.

\section{GRUPOS ETÁRIOS, SEXO E MORTALIDADE RESPECTIVA}

Dos 31 casos por nós estudados 18 eram homens e 13 mulheres.

A bacteremia foi mais freqüente no grupo etário de 51-60 anos. A maior incidência de mortalidade foi no grupo de 41-50 anos.

$\mathrm{Na}$ literatura tem-se encontrado esta mesma distribuiçāo, como em recente revisão de 303 casos da Mayo Clínic (4), em que a bacteremia era mais freqüente no sexo masculino na proporção de 2:1, sendo que $75 \%$ dos casos ocorreu em homens acima de 50 anos, o que corresponde ao grupo etário onde é mais freqüente a manipulação urológica.

\section{FATÖRES PREDISPONENTES}

O uso prévio de antibióticos foi o fator predisponente mais comum por nós verificado, ocorrendo em 21 dos 31 casos estu-

\section{PORTA DE ENTRADA}

\begin{tabular}{l|c|c|}
\multicolumn{1}{c}{$\mathrm{N}^{\circ}$ de casos } & $\%$ \\
\cline { 2 - 3 } Trato urinário & 19 & $(61,3 \%)$ \\
Trato gastro-intestinal & 7 & $(22,6 \%)$ \\
Pele & 2 & $(6,5 \%)$ \\
Aparelho genital feminino & 1 & $(3,2 \%)$ \\
Trato respiratório & 1 & $(3,2 \%)$ \\
Ignorada & 1 & $(3,2 \%)$ \\
& &
\end{tabular}




\section{ORGANISMOS ETIOLÓGICOS E MORTALIDADE}

\begin{tabular}{|l|cccc|} 
& N. $^{\circ}$ & CASOS & MORTAL & $\%$ \\
\cline { 2 - 4 } Klebsiella-Aerobacter & 9 & 4 & 44 \\
Escherichia coli & 9 & 5 & 55 \\
Pseudomonas aeruginosa & 4 & 4 & 100 \\
Proteus & 3 & 2 & 66 \\
E. coli + P. aeroginosa & 2 & 2 & 100 \\
E. coli + Klebs. - Aerobacter & 2 & 0 & 0 \\
Paracolobactrum & 1 & 0 & 0 \\
Alcaligenes fecalis & 1 & 0 & 0 \\
\hline
\end{tabular}

dados. Admite-se inclusive que o aumento do número de casos de bacteremia por gram-negativos nos últimos anos seja devido em parte ao crescente uso de antibióticos de largo espectro $(3,4,6$ e 9$)$.

Este fato demonstra claramente que a flora gram-negativa freqüentemente age por mecanismo de superinfecção devido às suas condições biológicas de flora entérica e altamente resistente aos antibióticos e quimioterápicos. Este fato foi comprovado em nossa série desde que 21 pacientes estavam em uso prévio de antibióticos.

"Diabetes mellitus", neoplasias malignas, litíase biliar e hiperplasia prostática foram os outros fatôres predisponentes encontrados, ao lado do uso de esterói̇des, citostáticos e quimioterapia.

\section{FATÔRES PRECIPITANTES}

É, sem dúvida nenhuma, a manipulação do aparelho urinário o grande fator precipitante no desencadeamento de uma bacteremia por gram-negativo. A histór:a de um simples cateterismo vesical prévio, de uma cirurgia prostática ou de uma cistoscopia num indivíduo geralmente idoso e que apresenta, algumas horas após, febre calafrios e hipotensão nos levam a pensar firmemente na hipótese diagnóstica de uma bacteremia por gram-negativo.

Dos 31 casos por nós estudados, 13 apresentavam indiscutivel antecedente de manipulação urológica e consequiente infecção urinária.

Outro elemento importante referido na história dêsses doentes é a cirurgia do aparelho digestivo, habitat comum dêsses germes, principalmente intestino e vias biliares. Os indivíduos que apresentam obstrução das vias biliares ou obstrução urinária são também sérios candidatos ao desenvolvimento de uma bacteremia por gram-negativo.

\section{QUADRO CLINICO E LABORATORIAL}

As manifestações clinicas essenciais exibidas por êsses pacientes são febre. calafrios, taquipnéia, alteração do comportamento principalmente em pacientes idosos tais como agitação, delírio, confusão mental, torpor e até mesmo coma. A hipotensão arterial é freqüentemente observada nesses indivíduos bem como diminuição do volume urinário. Icterícia não raramente é observada. Algumas vêzes cianose de extremidades e choque estão presentes e são sinais de mau prognóstico.

As septicemias causadas por Pseudomonas se caracterizam por apresentar leucopenia, lesões cutâneas constituídas por flictenas arroxeadas e necróticas, descritas como ectima gangrenoso, localizadas principalmente nas regióes axilar e perineal. Ocorre geralmente em doentes portadores de doença hematológica básica (agranulocitose, leucemia aguda).

As principais manifestaçóes laboratoriais observadas são uma discreta elevação na taxa de uréia sanguinea (elevações acentuadas na uréia e creatinina denotam uma agressão renal grave), uma baixa da 


\section{GRUPOS ETÁRIOS E MORTALIDADE RESPECTIVA}

\section{№de cosos SEXO $\left\{\begin{array}{l}\text { homens - } 18 \\ \text { mulheres - } 13\end{array}\right.$}

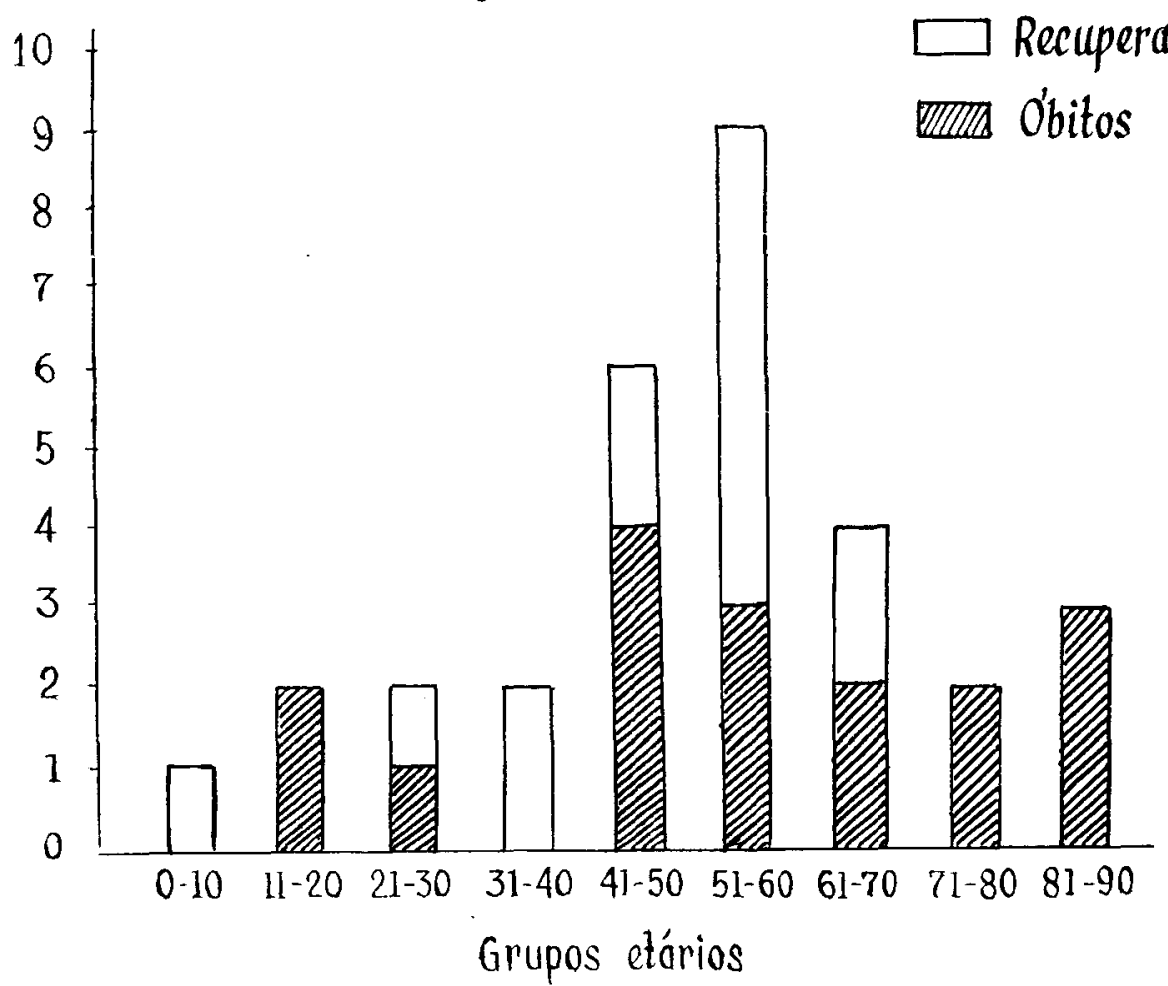

reserva alcalina, moderada elevação nas taxas de transaminases.

O hemograma revelou jeucocitose moderada a severa, com ausência de eosinófilos, linfopenia, desvio para a esquerda. e presença de granulacōes e vacúclos nos neutrófilos. Quadros de leucopenia ou sugestivos de agranulocitose têm sido relatados na literatura em casos de infecçōes por Pseudomonas.

Em presença de choque, as elevações de transaminases e amilase levam à confusão diagnostica com infarto do miocárciio $\mathrm{cu}$ pancreatite, respectivamente (8).

\section{COMPLICACŌES}

As principais complicações assinaladas foram:

1 .. Choque bacteriano
2 -. Insuficiência renal aguda

3 ... Superinfecção

4... Focos metastáticos pulmonares

5 - Insuficiência cardíaca

O choque bacteriano é a mais grave e a mais temivel complicaçāo de uma bacteremia por gram-negativcs. O choque ocorreu em aproximadamente $58 \%$ dos casos por nós estudados. Klebsiella-Aerobacter. $E$. coli e Pseudomonas aeruginosa foram os germes gram-negativcs que mais freqüentemente determinaram êste sindrome.

A sintomatologia do choque bacteriano de início difere da do choque habitual, caractericando-se por pele quente, pulso cheio, febre e hipotensão arterial, podendo mesmo se manter a diurese. E a chamada fase quente do choque. Com a evolução, o paciente passa e exibir sinais de perfusão baixa, taquipnéia mais acentuada, cianose 
MORTALIDADE

\begin{tabular}{|c|c|c|c|c|c|c|}
\hline \multirow[b]{2}{*}{ HOMENS } & \multicolumn{2}{|c|}{ BACTEREMIA } & \multicolumn{2}{|c|}{$\begin{array}{c}\text { CHOQUE } \\
\text { BACTERIANO }\end{array}$} & \multicolumn{2}{|c|}{ TOTAIS } \\
\hline & $0 / 6$ & $0 \%$ & $10 / 12$ & $83,3 \%$ & $10 / 18$ & $55,5 \%$ \\
\hline MULHERES & $4 / 7$ & $57,1 \%$ & $3 / 6$ & $50,0 \%$ & $7 / 13$ & $53,8 \%$ \\
\hline TOTAIS & $4 / 13$ & $30,7 \%$ & $13 / 18$ & $72,2 \%$ & $17 / 31$ & $54,8 \%$ \\
\hline
\end{tabular}

mais evidente, pele fria, úmida e pegajosa com pulso filiforme. A pressão arterial se encontra em niveis muito baixos, queda do volume urinário, caracterizando assim o estado de choque frio, que é sempre de prognóstico muito grave.

$O$ indice de mortalidade ncs pacientes em choque é de $30-80 \%$ na literatura (4. $5,8,11,12$ e 13), e em nossa casuistica a mortalidade foi de $83 \%$ nos homens e $50 \%$ nas mulheres.

A insuficiência renal aguda foi outra complicação freqüente e geralmente é conseqüência dc choque, aumentando a gravidade do quadro pois limita fundamentalmente a administraçãc de antibióticos tão importantes para o contrôle da infecção.

Outra complicação grave e que deve ser sistemàticamente pesquisada e pensada é a superinfecção pcr fungos, estafilococos

\begin{tabular}{l|rr}
\multicolumn{1}{c|}{ COMPLICAC̣̃̃ES } & N. de casos $\%$ \\
\hline Choque & 18 & 58,1 \\
Insuficiência renal aguda & 7 & 22,6 \\
Superinfecçáo & 4 & 13,0 \\
Pneumopatia & 4 & 13,0 \\
Insuficiência cardiaca & 3 & 9,7 \\
\hline
\end{tabular}

\section{ORGANISMOS ETIOLÓGICOS E CHOQUE BACTERIANO}

\begin{tabular}{l|cc}
\hline \multicolumn{1}{c|}{ GERME } & N. CASOS & \\
\cline { 2 - 3 } Klebs.-Aerob & 5 & 27.7 \\
E. coli & 5 & 27.7 \\
P. aerug. & 3 & 16.7 \\
Proteus & 2 & 11.2 \\
E. coli + P. aerug. & 2 & 11.2 \\
E. coli + Klebs.-Aerob. & 0 & 0 \\
Paracolabactrum & 1 & 5.5 \\
A. Fecalis & 0 & 0 \\
\multicolumn{1}{r}{$\quad$ TOTAL } & 18 & 58.1 \\
\hline
\end{tabular}

ou mesmo um outro germe gram-negativc mais resistente como o Pseudomonas.

Os abscessos metastáticos são mais encontrados em bacteremias por Bacteróides є Pseudcmonas.

\section{FATÔRES PRECIPITANTES}

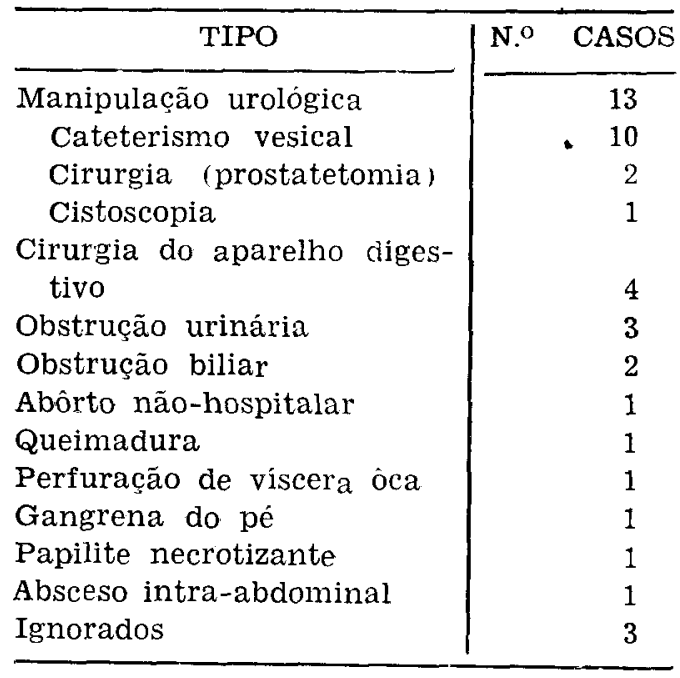

FATORES PREDISPONENTES

\begin{tabular}{|c|c|c|}
\hline TIPO & N. ${ }^{\circ}$ & CASOS \\
\hline Uso prévio de antibióticos & & 21 \\
\hline Diabetes mellitus & & 7 \\
\hline Neoplasia maligna & & 5 \\
\hline Litiase biliar & & 3 \\
\hline Hiperplasia prostática & & 3 \\
\hline Litiase ureteral & & 2 \\
\hline $\begin{array}{l}\text { Uso prévio de esteroides, } \\
\text { citostáticis ou radiotera- } \\
\text { pia (uma vez cada) }\end{array}$ & & 3 \\
\hline Arterioesclerose obliterante & & 2 \\
\hline Diversos * & & 8 \\
\hline
\end{tabular}


ORGANISMOS ETIOLÓGICOS E PORTA DE ENTRADA

\begin{tabular}{|c|c|c|c|c|c|c|c|c|}
\hline & $\begin{array}{l}\mathrm{N}^{\circ} \text { de } \\
\text { casos }\end{array}$ & $\%$ & $\begin{array}{l}\text { Trato } \\
\text { urinário }\end{array}$ & $\begin{array}{l}\text { Trato gastro- } \\
\text { intestinal }\end{array}$ & Pele & $\begin{array}{l}\text { Trato } \\
\text { respirat. }\end{array}$ & $\begin{array}{l}\text { Ap. genital } \\
\text { feminino }\end{array}$ & Ignorado \\
\hline $\begin{array}{l}\text { Klebsiella-Aerobacter } \\
\text { E. coli } \\
\text { P. aeruginosa } \\
\text { Proteus } \\
\text { E. coli + P. aerug. } \\
\text { E. coli + Klebs.-Aerob. } \\
\text { Paracolobactrum } \\
\text { Alcaligenes Fecalis }\end{array}$ & $\begin{array}{l}9 \\
9 \\
4 \\
3 \\
2 \\
2 \\
1 \\
1\end{array}$ & \begin{tabular}{r|}
$29 \%$ \\
$29 \%$ \\
$12,9 \%$ \\
$9,7 \%$ \\
$6,5 \%$ \\
$6,5 \%$ \\
$3,2 \%$ \\
$3,2 \%$
\end{tabular} & $\begin{array}{l}5 \\
6 \\
3 \\
3 \\
\\
1 \\
1\end{array}$ & $\begin{array}{l}3 \\
2 \\
1 \\
1\end{array}$ & 1 & 1 & 1 & 1 \\
\hline $\begin{array}{c}\text { TOTAIS } \\
\%\end{array}$ & 31 & & $\begin{array}{l}19 \\
61,3\end{array}$ & $\begin{array}{c}7 \\
22,6\end{array}$ & $\begin{array}{l}2 \\
6,5\end{array}$ & $\begin{array}{r}1 \\
3,2\end{array}$ & $\begin{array}{c}1 \\
3,2\end{array}$ & $\begin{array}{c}1 \\
3,2\end{array}$ \\
\hline
\end{tabular}




\section{TERAPËUTICA}

Baseia-se fundamentalmente na instituição da terapêutica específica o mais precoce possivel, qualitativa e quantitativamente satisfatória, além do tratamento suportivo suplementar indispensável.

Após colheita de sangue para hemccultura e antibiograma, inicia-se a antibióticoterapia com um dos seguintes esquemas que se seguem até a chegada dos exames solicitados.

I - Estreptomicina (1 a 2 g/dia) Tetraciclina (1.5 a $2 \mathrm{~g} /$ dia) ou Cloranfenicol ( $2 \mathrm{~g} / \mathrm{dia})$.

II - Kanamicina (1.5 a $2 \mathrm{~g} /$ dia $)+$ Tetraciclina ou Cloranfeniccl.

III - Quando há suspeita de que o germe causador é o Pseudomonas - Colistin $(1.000 .000$ unid. $8 / 8$ ou $12 / 12 \mathrm{~h})+$ Tetraciclina ou Cloranfenicol.

IV - Penicilina G-20 a 80 milhōes de unidades diárias, isolada ou em associação com Estreptomicina cu um dos derivados da Cefalosporina $\mathbf{C}$ ou com a Kanamicina.

$\mathrm{V}$ - Ampicilina (4 $\mathrm{g} /$ dia, isolada ou associada com a Kanamicina).

VI - Derivados da Cefalosporina $\mathbf{C}-$ Cefaloridina ( 2 a $4 \mathrm{~g} /$ dia) ; Cefalotina ( 6 a $8 \mathrm{~g} /$ dia): são utilizados isolada ou em combinação com Penicilina G ou Kanamicina.

VII - Recentemente surgiu a Gentamicina, antibiótico de largo espectro indicado especialmente em infecções ocasionadas por Pseudomonas, e ainda com boa atividade sôbre $E$. coli e Klebsiella-Aerobacter, utilizada na dose de $120 \mathrm{mg} / 24$ horas.

Caso o paciente não melhore nas primeiras 24 hcras o esquema deverá ser revisto até a época do resultado do antibio- grama, e a troca por êste far-se-á sòmente na ausência de melhora.

Nos casos do uso dêsses esquemas onde o espectro amplo e doses elevadas são utilizadas, a superinfecção é uma complicação muito freqüente e sempre grave. É de boa conduta a execução diária de culturas de fezes, urina e escarro na tentativa de um diagnóstico precoce dessa complicacão. Do ponto de vista clínico ela é suspeitada quando após uma resposta adequada ao esquema terapêutico instituído, houver uma brusca piora sem outra complicação que 0 justifique.

$\mathrm{Na}$ presença de infecçōes incontroláveis, focos abscedidos não observados devem ser procurados, e a drenagem dos mesmos é uma indicação que sempre se impōe.

Caso sobrevenha o choque, além das medidas habituais para tais casos e da terapêutica acima descrita, acrescente-se 0 ccntrôle hemodinâmico, com pressão venosa central contínua, uso adequado de vasopressores, corticóides, estimuladores betaadrenérgicos e bloqueadores alfa adrenérgicos

\section{MORTALIDADE}

$O$ indice de mortalidade foi de aproximadamente $30,7 \%$ nos casos de simples bacteremia e de $72,2 \%$ em bacteremias acompanhadas de choque.

Pseudomonas aeruginosa, isolado ou associado a $E$. coli, levou à morte em $100 \%$ dos casos.

\section{PROGNÔSTICO}

O prognóstico depende fundamentalmente da doença básica, da presença ou não de choque, da precocidade do diagnóstico e da instalação de uma terapêutica imediata e eficaz. 


\section{$S U M M A R Y$}

Gram-negative infection is a serious complication and a great deal of attention has been paid to it lately.

The aa. present 31 cases of gram-negative infeciion. The most common organisms were Escherichia coli and Klebsiella-Aerobacter (58\% of the cases) followed by the Pseudomonas group. Males were more affected than female. In $61,3 \%$ of the cases the urinary tract was the site of infection.

Previous treatment occurred in several patients. the most important being antibiotics, steroids and cytostatics. nancy.

The most frequent predisposing diseases vere diabetes mellitus and malig-

Urinary tract manipulation (with previous infection or without it), gastrointestinal surgery and urinary or biliary obstruction were main precipitants.

Chiils, fever and low blood pressure were the most frequent clinical manif.. estations. Shock ocurred in $58 \%$ of the cases, which is a very high incidence when compared with other statistics. Acute renal insuficiency, super-infection and metastatic lung infection also ocurred.

General therapeutic considerations as well as antibiotic administration schedules are suggested by the authors.

Mortality due to simple bacteremia was $30,7 \%$, the association of bacteremia and shock raised this figure to $72,2 \%$. Pseudomonas infection gave $100 \%$ mortality.

\section{BIBLIOGRAFIA}

1.. EICKOFF, T. C., STEINHAUER, B. W. \& FINLAND, M. - The Klebsiella-Entercbacter-Serratia division. Biochemical and serologic characteristics and susceptibility to antibio. ties. Ann. Int. Med. 65: 1163, 1956.

2 ... FINLAND, MAXWELL, JONES $W$. F., Jr. \& BARNES MILDRED, W. Occurrence of serious bacterial infections since introducticn of antibacterial agents. J. A. M. A. 170: 2183, 1959.

3 -. KATZ, S. - Infectious disease enrexgencies. M. Clin. North America. 46: 473, 1962 .

4 -.- MARTIN $W$. J. - Bacteremia due to gram-negative bacilli. Journal of the Indian Medical Profession 11: $5218,1965$.

5 - MC CABE, W. R. \& JACKSON, G. G. Gram-negative bacteremia. I. Etiology and ecology. II. Clinical, laboratory and therapeutic observations. Arch. Int. Med. 110: 847 1962 .

6 MC HENRY, M. C., BAGGENSTOSS, A. H. \& MARTIN, W. - - Bacteremia die to gram-negative bacilli. Clinical and autopsy findings in 33 cases. Am. J. Clin. Path. 50: 160, 1958.
7 - RODGERS, D, E. ... The changine pattern of life threatening nucrobial disease. New England J. Meci. 261: $677,1959$.

8- SHUBIN, H., \& WEIL, M. H. Bacterial shock. J. A. M. A. 135: 950, 1963.

9 - STEINHAUER, B. W., EICKOFF, 'J C. KISLAK, J. W. \& FINLAND, M. - The Klebsiella-Enterobactel.. -Serratia division. Clinical and epidemiologic characteristcs. Ann. Int Med. 65: 1180, 1966

10 - TILLOTSON, J. R. \& LERNER. A. M. - Pneumonias caised by gram negative bacili. Medicine. 45 : 65, 1966 .

11 -- WAISBREN, B. A. -- Gram-negative shock and endctoxin shock. Editorial. Am. J. Med. 36: 819, 1994.

12 - WAISBREN, B. A. \& ARENA, J. - Shock associated with bacteremia due to gram-negative bacilli: Autopsy findings. Arch, Int. Med. 116: 336,1965

13 - WEIL, M. H. \& SPINK, W. W. The shcck syndrome associated with bacteremia due to gram-negative bacilli. Arch. Int. Med. 101: 184, 1958. 